\title{
CONDIÇÕES FÍSICAS E HIGIÊNICO-SANITÁRIAS DOS MATADOUROS MUNICIPAIS DA REGIÃO OESTE DO RIO GRANDE DO NORTE, BRASIL
}

\section{A.I. Leite, A.R.A. de Queiroz, J.O. Moreira, J.S. Batista, E. Pereira Neto, C.G. Mendes, J.B.A. da Silva ${ }^{1}$}

Universidade Federal Rural do Semi-Árido, Departamento de Ciências Animais, BR 110, km 47, Costa e Silva, CEP 59625-900, Mossoró, RN, Brasil. E-mail: alex@ufersa.edu.br

\section{RESUMO}

\begin{abstract}
Foram avaliadas as condições dos matadouros municipais da região oeste do Rio Grande do Norte, sendo levado em consideração seus aspectos higiênico-sanitários, as condições físicas das instalações, os procedimentos de matança, higiene de pessoal, ambiente, equipamentos e utensílios. Foram visitados 15 abatedouros municipais nos quais foi aplicado questionário epidemiológico e realizada entrevista com o responsável pelo estabelecimento. Foi observado que $66,7 \%$ dos matadouros estavam construídos em zona urbana. Em $80 \%$ dos estabelecimentos não havia inspeção sanitária de rotina. Os matadouros não seguiam a recomendação do abate humanitário. Todo o procedimento de abate (insensibilização, sangria, esfola e evisceração) era realizado no chão dos matadouros. Diante do exposto, foi percebido que as condições higiênicosanitárias eram extremamente precárias, as instalações físicas estavam impróprias e os manipuladores das carnes não atendiam às exigências mínimas de higiene. Portanto, um importante e negligenciado problema de saúde pública foi evidenciado, necessitando que providências sejam urgentemente tomadas por órgãos competentes e responsáveis pelos estabelecimentos.
\end{abstract}

PALAVRAS-CHAVE: Abate, aspectos higiênicos, inspeção municipal, risco microbiológico.

\section{ABSTRACT}

PHYSICALANDHYGIENIC-SANITARYCONDITIONSOFTHECOUNTYSLAUGHTERHOUSES IN THE WESTERN REGION OF RIO GRANDE DO NORTE STATE, BRAZIL. The conditions of the county slaughterhouses of the western region of Rio Grande do Norte State, Brazil, were evaluated taken into account hygienic-sanitary aspects, the physical conditions of the facilities, the slaughter procedures, staff hygiene, atmosphere, equipment and utensils. Visits were made to each of 15 municipal slaughterhouses, where an epidemiological questionnaire was completed and an interview was made with the person in charge of the establishment. It was observed that $66.7 \%$ of the slaughterhouses were located in urban areas. In $80 \%$ of the establishments there was no routine sanitary inspection. The slaughterhouses did not follow the recommendations for humane slaughter. The whole slaughter procedure (stunning, bleeding, skinning and evisceration) was carried out on the floor of the slaughterhouses. In light of the findings, it was perceived that the hygienic-sanitary conditions were extremely precarious, and the physical facilities were inappropriate. The handlers of the meats did not comply with the minimum demands of hygiene. An important and neglectful problem of public health was evidenced, indicating that corrective measures should beimplemented urgently by the relevant agencies and by the people in charge of the establishments.

KEY WORDS: Slaughter, hygienic aspects, county inspection, microbiological risk.

\section{INTRODUÇÃO}

A qualidade de um produto cárneo pode ser observada sob duas perspectivas. Uma objetiva, que é representada por um conjunto de características intrínsecas ao produto, que são as características físicas, nutricionais e higiênicas do produto. Outra subjetiva associada às preferências do consumidor, ou seja, seus gostos pessoais no que diz respeito à qualidade sensorial, que é composta de um conjunto de características sensoriais que levam à aceitação ou rejeição do produto: apresentação do produto, forma, textura, sabor, imagem da marca, etc. (GERLACK et al., 2001).

Omatadouro ou abatedouroéum estabelecimento dotado de instalação adequada para a matança de quaisquer das espécies de açougue, visando o fornecimento de carne "in natura" ao comérciointerno, com ou sem dependências para a industrialização; disporá obrigatoriamente, de instalação e aparelhagem 
para o aproveitamento completo e perfeito de todas as matérias-primas e preparo de subprodutos não comestíveis (BRASIL, 2008).

De acordo com RouQuAYrol; AlmeIdA FiLho(2003), a maior parte dos municípios brasileiros não desenvolve ações de inspeção dos produtos de origem animal, nem dispõe de condições adequadas de abate. Além dos riscos de veiculação de doenças transmissíveis por alimentos (DTA's), há risco de outros agravos relacionados com resíduos tóxicos, fármacos, anabolizantes e hormônios nos alimentos que não são detectados nas inspeções e análises comuns.

Os alimentos de origem animal consumidos pelo homem, podem sercontaminados pormicro-organismos patogênicos durante qualquer uma das etapas de produção, manipulação, armazenamento, distribuição e transporte, ressaltando que, além do risco atribuído ao processo de industrialização, as precárias condições físicas dos locais de abate dos animais e a falta de fiscalização da comercialização dos produtos podem afetar ainda mais a qualidade destes alimentos (Silva, 1999).

Os matadouros municipais, principalmente os de pequeno porte, em sua maioria não atendem aos requisitos mínimos de higiene ao longo do fluxograma de abate, não oferecem segurança para os manipuladores na produção e, principalmente, não garantem um alimento cárneo livre e protegido de contaminações física, química e biológica, proveniente do homem, dos animais e do meio ambiente. Desta forma, o presente trabalho objetivou avaliar as condições físicas (das construções, instalações, equipamentos e utensílios) e higiênicas (pessoal, instalações e equipamentos) oferecidas pelos matadouros municipais da região oeste do Rio Grande do Norte.

\section{MATERIAL E MÉTODOS}

O trabalho foi realizado na região oeste do Estado do Rio Grande do Norte que apresenta 61 municípios dentre estes o presente trabalho avaliou 15 municípios. Para a obtenção da amostra os municípios foram estratificados em cinco grupos de acordo com o número de habitantes, sendo: (GRUPO I) representado por 26 municípios com menos de 5.000 habitantes; (GRUPO II) apresentava 17 municípios entre 5.000 e 9.999; (GRUPO III) era formado por nove municípios entre 10.000 e 14.999; (GRUPO IV) representado por três municípios, entre 15.000 e 19.999 e (GRUPO V) com seis municípios com 20.000 ou mais habitantes. $\mathrm{O}$ trabalho avaliou seis municípios do GRUPOI, quatro do GRUPO II, dois do GRUPO III, um do GRUPO IV e dois do GRUPO V. A quantidade de municípios avaliados pelos grupos foi proporcional a sua totalidade.

As coletas dos dados foram realizadas de junho a novembro de 2001, sendo avaliadas as condições higiênico sanitárias e edificações das instalações, manutenção e higiene dos equipamentos, além da higiene dos manipuladores em 15 matadouros durante duas visitas em cada estabelecimento.

Utilizou-se um roteiro epidemiológico para obter informações de identificação e das condições relativas à localização; instalações; procedimentos de matança; higiene do pessoal, do ambiente, equipamentos e utensílios; transporte e destino do produto final. Os dados foram avaliados em formas de tabelas, e estas apresentam as freqüências simples e relativas dos dados.

Os resultados foram comparados com a legislação federal que trata do regulamento de inspeção industrial dos produtos de origem animal, visto que não existe lei nos municípios avaliados acerca dos itens que foram estudados, e no Estado não há lei que contemple esse assunto.

\section{RESULTADOS E DISCUSSÃO}

Avaliando os dados gerais dos matadouros (Tabela 1), constatou-se que, dentre os matadouros vistoriados, $14(93,3 \%)$ pertencia à administração pública municipal e apenas um $(6,7 \%)$ a rede privada, todos apresentavam Serviço de Inspeção Municipal (SIM). A comercialização era realizada no próprio município (93,3\%), com exceção de um matadouro $(6,7 \%)$ que fornecia carne também para municípios circunvizinhos, sendo isto uma prática ilegal, visto que a comercialização intermunicipal só é permitida se o estabelecimento apresentar Serviço de Inspeção Estadual - SIE (BRASIL, 2008).

Outro problema muito comum observado nos matadouros públicos municipais foi ausência do Médico Veterinário em 66,7\% dos casos e, mesmo nos estabelecimentos que apresentavam aqueles, a realização da inspeção não era uma prática rotineira (80\%) (Tabela 1), sendo esta prática atribuição exclusiva do médico veterinário (BRASIL, 2008).

O consumo de carne de baixa qualidade pode representar riscosaoconsumidor, tais comozoonoses, toxininfecções e intoxicações alimentares por microorganismos. Deve-se avaliar a importância da Inspeção Veterinária antes, durante e após o abate dos animais como condição impositiva para reduzir ao mínimo as ocorrências que influem na qualidade ena sanidade da carne (PARDi et al., 2001).

WALtz et al. (2007), estudando a importância da inspeção final na qualidade da carne, concluíram 
Tabela 1 - Dados gerais dos matadouros municipais estudados na região oeste do Rio Grande do Norte, 2001.

\begin{tabular}{llc}
\hline Variavel & & Frequência (\%) \\
\hline Pertencente ao poder: & Público & $14(93,3)$ \\
& Privado & $01(6,7)$ \\
Comercialização: & Intramunicipal & $14(93,3)$ \\
& Intermunicipal & $01(6,7)$ \\
Médico veterinário: & Presente & $05(33,3)$ \\
& Ausente & $10(66,7)$ \\
Espécies abatidas: & Só Bovinos & $07(46,7)$ \\
& Bovinos e Suínos & $02(13,3)$ \\
& Bovinos + Suínos + Ovinos & $02(13,3)$ \\
& Bovinos + Suínos + Caprinos + Ovinos & $04(26,7)$ \\
\hline
\end{tabular}

que esta prática tem grande valor no controle das patologias, mostrando-se rigorosa na segurança alimentar, uma vez que várias doenças foram encontradas, inclusive zoonoses como cisticercose e tuberculose.

Foi observado que em 46,7\% dos matadouros eram abatidos somente bovinos, o que propiciava o abate das outras espécies em locais que não fosse o matadouro. Segundo Oliveira (1999); Freitas et al. (1999) e FERNANDEZ;R EZENDE (2002), este tipo de abate realizado em local inapropiadoé um sério problema urbano contemporâneo, está relacionado a fatores de natureza sócio-econômica e apresenta reflexos na comunidade, por causa das péssimas condições higiênicas e sanitárias dos alimentos produzidos, poluição do meio ambiente e propagação de patógenos, representando, portanto, um sério risco para a saúde coletiva.

A maior parte dos matadouros $(66,7 \%)$ estava construída na zona urbana (Tabela 2). SANTos et al. (2007), ao analisarem o abatedouro frigorífico no Município de Mossoró, também observaram que esse ficava localizado em zona urbana o que causava o desconforto da população residente nas proximidades devido à produção de odores desagradáveis, além de atrair insetos e roedores. Segundo BRASIL (2008), o funcionamento de estabelecimentos de carnes e derivados só pode ser autorizado dentro do perímetro urbano ou suburbano, depois de ouvida a autoridade de Saúde Pública e a Prefeitura Municipal locais.

Os matadouros apresentavam pequeno porte, com iluminação inadequada em $60 \%$ dos estabelecimentos, prejudicando o serviço de inspeção, porém eram suficientemente ventilados (Tabela 2). De acordo com a legislação federal (BRASIL, 2008), os estabelecimentos de produtos de origem animal devem dispor deluz natural e artificial abundantes, bem como de ventilação suficiente em todas as dependências, respeitadas as peculiaridades de ordem tecnológica cabíveis. Devendo sempre realizar o julgamento de carcaças com tonalidade amarela ou amarelo-esverdeada com luz natural.
Tabela 2 - Aspectos sanitários gerais, instalações internas e características da sala de matança dos matadouros municipais da região oeste do Rio Grande do Norte, 2001.

\begin{tabular}{|c|c|c|}
\hline Variável & & uência (\%) \\
\hline Local de construção: & $\begin{array}{l}\text { Zona urbana } \\
\text { Zona rural }\end{array}$ & $\begin{array}{l}10(66,7) \\
05(33,3)\end{array}$ \\
\hline Vias de acesso: & $\begin{array}{l}\text { Adequado } \\
\text { Inadequado }\end{array}$ & $\begin{array}{l}11(73,3) \\
04(26,7)\end{array}$ \\
\hline Iluminação: & $\begin{array}{l}\text { Suficiente } \\
\text { Insuficiente }\end{array}$ & $\begin{array}{l}06(40,0) \\
09(60,0)\end{array}$ \\
\hline Ventilação: & $\begin{array}{l}\text { Adequado } \\
\text { Inadequado }\end{array}$ & $\begin{array}{c}15(100,0) \\
-\end{array}$ \\
\hline $\begin{array}{l}\text { Currais de chegada, de } \\
\text { matança e de observação: }\end{array}$ & $\begin{array}{l}\text { Presença } \\
\text { Ausência }\end{array}$ & $\begin{array}{l}06(40,0) \\
09(60,0)\end{array}$ \\
\hline Descanso e jejum hídrico: & $\begin{array}{l}\text { Existente } \\
\text { Inexistente }\end{array}$ & $\begin{array}{l}12(80,0) \\
03(20,0)\end{array}$ \\
\hline $\begin{array}{l}\text { Banho dos animais: } \\
\text { antes do abate: }\end{array}$ & $\begin{array}{l}\text { Presença } \\
\text { Ausência }\end{array}$ & $\begin{array}{l}03(20,0) \\
12(80,0)\end{array}$ \\
\hline Boxe de atordoamento: & $\begin{array}{l}\text { Adequado } \\
\text { Inadequado }\end{array}$ & $\begin{array}{l}05(33,3) \\
10(66,7)\end{array}$ \\
\hline Piso: & $\begin{array}{l}\text { Adequado } \\
\text { Inadequado }\end{array}$ & $\begin{array}{l}02(13,3) \\
13(86,7)\end{array}$ \\
\hline Revestimento de paredes: & $\begin{array}{l}\text { Adequado } \\
\text { Inadequado }\end{array}$ & $\begin{array}{l}03(20,0) \\
12(80,0)\end{array}$ \\
\hline Lavatórios de mãos: & $\begin{array}{l}\text { Suficiente } \\
\text { Insuficiente }\end{array}$ & $\begin{array}{l}02(13,3) \\
13(86,7)\end{array}$ \\
\hline Vestuários e armários: & $\begin{array}{l}\text { Presença } \\
\text { Ausência }\end{array}$ & $\begin{array}{l}01(6,7) \\
14(93,3)\end{array}$ \\
\hline $\begin{array}{l}\text { Banheiro em condições de } \\
\text { uso: }\end{array}$ & $\begin{array}{l}\text { Presença } \\
\text { Ausência }\end{array}$ & $\begin{array}{l}12(80,0) \\
12(80,0)\end{array}$ \\
\hline $\begin{array}{l}\text { Instalações para serviço } \\
\text { administrativo: }\end{array}$ & $\begin{array}{l}\text { Presença } \\
\text { Ausência }\end{array}$ & $\begin{array}{l}12(80,0) \\
12(80,0)\end{array}$ \\
\hline Provimento de água: & $\begin{array}{l}\text { Suficiente } \\
\text { Insuficiente }\end{array}$ & $\begin{array}{l}10(66,7) \\
05(33,3)\end{array}$ \\
\hline Tratamento de esgoto: & $\begin{array}{l}\text { Presença } \\
\text { Ausência }\end{array}$ & $\begin{array}{l}04(26,7) \\
11(73,4)\end{array}$ \\
\hline
\end{tabular}


Foram observadas inadequações nas instalações físicas como piso permeável e sem material adequado $(86,7 \%)$, revestimento de paredes $(80 \%)$ e junções paredes/piso (100\%) dos estabelecimentos (Tabela 2), dificultando assim, a higienização das instalações, favorecendo a retenção de sujidades com consequente proliferação de micro-organismos. BRASIL (2008) os ângulos entre paredes e pisos serão arredondados com o mesmo material de impermeabilização.

A maioria não apresentava instalações (Tabela 2) para serviços administrativos $(80 \%)$, nem vestuários ou armários $(93,3 \%)$, como também banheiro em condições de uso $(80 \%)$. Os lavatórios de mãos eram insuficientes e/ou inadequados $(86,7 \%)$, favorecendo a ausência de práticas higiênicas e contaminações cruzadas da carne. De acordo com a legislação (BRASIL, 2008), os estabelecimentos devem dispor de rouparia, vestiários, banheiros, privadas, mictórios e demais dependências necessárias, em número proporcional ao pessoal, instaladas separadamente para cada sexo, completamente isolados e afastados das dependências onde são beneficiados produtos destinados à alimentação humana.

Em $60 \%$ dos casos os estabelecimentos não possuíam currais de chegada e seleção, observação e matança (Tabela 2), os animais ficavam em um único curral, dificultando o trabalho de inspeção ante-mortem por parte do médico veterinário.

O descanso e jejum hídrico não foram verificados em 20\% dos casos (Tabela 2). O jejum alimentar tem por objetivo diminuir a contaminação com resíduos alimentares ou intestinais, evitando que carcaças sejam desperdiçadas, e melhorar a eficiência na produção (DuKEet al., 1997; NorthCutT et al., 1997;SAVAGE, 1998). Dentre os fatores que antecedem o abate, o período de jejum de ração é o mais importante, pois pode evitar contaminações e prejuízos nos rendimentos das carcaças caso seja feito de maneira correta. Além disso, o jejum pré-abate pode reduzir os efeitos do estresse calórico, já que o metabolismo da ave é reduzido durante o jejum, e diminuir os riscos de contaminações de carcaças por rompimento de vísceras no abatedouro (SCHETtino et al., 2006).

Em todos os matadouros a movimentação dos animais (Tabela 2) era feita com material inadequado (pontiagudo), a condução dos animais até a linha de abate deve ser executada de maneira o menos estressante possível, isso será atingido levando-se em consideração os aspectos construtivos das instalações (Pereira; Lopes, 2006). Outro fator importante é quanto à presença de pontos metálicos que possam provocar reflexos, ou ruídos de alta intensidade, pessoas ao redor, locais escuros podem representar barreiras que afetarão o avanço normal dos animais pela linha de abate (FilHo; Silva, 2004).
Apenas 20\% dos matadouros realizavam o banho dos animais antes do abate (Tabela 2). Segundo RoçA (2001), este banho não interfere na sangria, mas serve para limpeza do couro, evitando contaminação do ambiente e carcaça.

Oboxe de atordoamento estava ausente em $(66,7 \%)$ dos matadouros (Tabela 2), sendo o animal abatido em meio a sala de matança, a maioria das vezes contido com cordas e preso à argolas de ferro inseridas no piso, aumentando o estresse e contusão do animal, além de favorecer a ocorrência de acidentes com o pessoal de trabalho.

$\mathrm{O}$ método de abate era inadequado em todos os estabelecimentos, o mesmo se dava com o uso de marretas para a insensibilização dos animais seguida da sangria. A esfola aérea não era utilizada em nenhum dos matadouros, devido à inexistência de trilhos aéreos, sendo realizada diretamente no piso da sala de matança, propiciando a contaminação da carcaça. Estes resultados são similares aos que foram observados por Freitas et al. (2006), onde as condições higiênicas eram mínimas para atordoamento, sangria e evisceração dos animais que eram, na maioria dos locais, realizadas diretamente no solo e ou no piso cimentado. Segundo BrasiL (2008), sóé permitido o sacrifício de animais de açougue por métodos humanitários, utilizando prévia insensibilização baseada em princípios científicos, seguida de imediata sangria.

$\mathrm{O}$ abastecimento de água era insuficiente em $33,3 \%$ dos estabelecimentos (Tabela 2), discordando com BRASIL (2008), onde diz que este deve dispor de rede de abastecimento de água para atender suficientemente as necessidades do trabalho industrial e às dependências sanitárias. Em 33,3\% a água era oriunda de fontes alternativas como cacimba, poço, lagoa ou açude sem passar por nenhum tipo de tratamento ou exame microbiológico antes de ser utilizada sendo que, dessa forma, seria impossível saber a quantidade de micro-organismos existentes. BRASIL (2008) a água de abastecimento deve ser potável, e quando apresentar mais de 500 micro-organismos/ $\mathrm{mL}$ deverá passar por outra análise confirmatória antes de condená-la.

Quanto ao tratamento de esgotos(Tabela 2), na sua maioria $(73,4 \%)$ os resíduos não sofriam tratamento e eram despejados a céu aberto. De acordo com SCHOENHALs (2006) nos matadouros e frigoríficos, os efluentes são gerados em grande quantidade e representam um problema sério pelo seu alto teor de matéria orgânica e o lançamento desses despejosin natura acarreta sérios prejuízos ao meio ambiente.

Os vestuários não apresentavam todos os equipamentos de proteção individual necessário a realização do abate. As práticas de higiene dos equipamentos e instalações não eram realizadas diariamente, 
além disso, não utilizavam água sobre pressão, o que facilitaria a remoção de restos de matéria orgânica das instalações. Os trabalhadores não passavam por exames médicos periódicos e não havia exigência de carteiras de saúde. Segundo BRASIL (2008), os operários que trabalham na indústria de produtos de origem animal serão portadores de carteira de saúde fornecida por autoridade sanitária oficial, devem apresentar condições de saúde e ter hábitos higiênicos; anualmente serão submetidos a exame em repartição de saúde pública, apresentando à inspeção federal as anotações competentes em sua carteira, pelas quais se verifique que não sofrem de doenças que os incompatibilizem com os trabalhos de fabricação de gêneros alimentícios.

Apesar de ser matadouros de inspeção oficial (SIM) em 93,3\% desses não havia as mínimas condições para realização de práticas de higiene geral do ambiente.

Foi comum a presença de animais domésticos no interior dos estabelecimentos (Tabela 3), como cães em $93,3 \%$ dos casos e gatos em $60,0 \%$, o controle rotineiro de pragas não existia em $93,3 \%$ dos estabelecimentos. De acordo com, BATISTA et al.(2004), estudando a soroprevalência de leptospiras em cães errantes na Cidade de Patos, Paraíba, entre os vários locais avaliados o que apresentou maior frequência de animais reagentes foi no matadouro público $(31,3 \%)$, segundo eles isso sugere o possível contato dos cães com tecidos provenientes de animais infectados abatidos.

O lixo (Tabela 3) não estava devidamente acondicionado $(73,7 \%)$, muitas vezes ficando acumulado, a céu aberto, nas proximidades dos matadouros. Semelhante ao relatado por FreITAs etal. (2006), que também observaram que o abate era realizado a céu aberto, nos casos extremos em fundo de quintal, onde se amontoam lixo, restos de materiais inservíveis, lama e valas de escoamento de água pluviais.

Tabela 3 - Avaliação da higiene geral dos matadouros municipais da região oeste do Rio Grande do Norte, 2001.

\begin{tabular}{lll}
\hline Variável & & Frequência (\%) \\
\hline Higiene geral do & Adequada & $01(6,7)$ \\
ambiente: & Inadequada & $14(93,3)$ \\
Animais domésticos & Presença de cães & $14(93,3)$ \\
nas proximidades: & Presença de gatos & $09(60,0)$ \\
Controle rotineiro de & Existente & $1(6,7)$ \\
pragas: & Inexistente & $14(93,3)$ \\
Acondicionamento do & Adequado & $04(26,7)$ \\
lixo: & Adequado & $11(73,4)$ \\
\hline
\end{tabular}

Havia presença de entulhos nas proximidades dos matadouros $(80,0 \%)$ e o fato de nenhum dos estabelecimentos possuírem proteção contra insetos e roedores, podendo implicar em riscos para a contaminação das carcaças. Segundo BRASIL (2008), os estabelecimentos devem ser mantidos livres de moscas, mosquitos, baratas, ratos, camundongos, quaisquer outros insetos ou animais.

\section{CONCLUSÃO}

Os matadouros da região oeste do Rio Grande do Norte estavam, na maioria fora do padrão recomendado pela legislação específica, estando instalados em local inadequado com inspeção rotineira precária ou inexistente; sem médico veterinário; em condições higiênicas e sanitárias extremamente carentes e com instalações físicas impróprias para a finalidade a qual se destinam.

\section{REFERÊNCIAS}

BATISTA, C. de S.A.; AZEVEDO, S.S. de.; ALVES, C..; VASCONCELLOS, S. A.; MORAIS, Z. M. de; CLEMENTINO, I. J.; LIMA, F. de S.; ARAUJO NETO, J. O. de Soroprevalência de leptospirose em cães errantes da cidade de Patos, Estado da Paraíba, Brasil. Brazilian Journal of Veterinary Research and Animal Science, v.41, n.2, p.131-136, 2004.

BRASIL. Ministério da Agricultura. Decreto n 30.691 de 29/03/1952 e alterado pela última vez pelo Decreto $\mathrm{n}^{\mathrm{o}} 6.385$, de 27 de fevereiro de 2008. Regulamento da inspeção industrial e sanitária de produtos de origem animal - RIISPOA. D.O. da União, 2008.

DUKE, G.E.; BASHA, M.; NOLL, S. Optimum duration of feed and water removal prior to processing in order to reduce the potential for fecal contamination in turkeys. Poultry Science, v.76, n.3, p.516-522, 1997.

FERNANDEZ, A.T.; REZENDE, R.C. Ocorrência de cisticercose em bovinos abatidos clandestinamente no município de Silva Jardim - RJ. 2002. Disponível em: $<$ http://crmvj.com.br/ivcong/bovinos.htm>. Acesso em: 10 abr. 2008.

FILHO, A.D.B.; SILVA, I.J.O. Abate humanitário: ponto fundamental do bem-estar animal. Revista Nacional da Carne, v.328, p.36-44, 2004.

FREITAS, J.A. et al. Abate clandestino e saúde pública realidade ou ficção. In: CONGRESSO ESTADUAL DE MEDICINA VETERINÁRIA; CONGRESSO DE MEDICINA VETERINÁRIA DO CONE SUL; EXPOSIÇÃO DE PRODUTOS E SERVIÇOS EM MEDICINA VETERINÁRIA. Gramado. Anais. Gramado: 1999. p.151. 
FREITAS, J. de A.; GALINDO, G. A. R.; SARRAF, K. de A.; OLIVEIRA, J.P. de; RAMOS, O.S.; HERRERA, D.E.S.; SANTOS, E.J.C. dos Situação atual e aspectos higiênicos e sanitários do abate clandestino, na região metropolitana de Belém, Pará. Higiene Alimentar, v.20, n.143, p.4549, 2006.

GERLACK, A.C.; TOLEDO, J.C.; LEÃO, R.C. Análise da gestão da qualidade na indústria da carne bovina do Estado de São Paulo. 2001. Disponível em: <http:/ / www.Fearp.usp.br/egna/resumos/Gerlack.pdf>. Acesso em: 12 mai. 2009.

NORTHCUTT, J.K.; SAVAGE, S.I.; VEST, L.R. Relationship between feed withdrawal and viscera condition of broilers. Poultry Science, v.76, p.410-414. 1997.

OLIVEIRA, G.C. A questão do abate clandestino de animais. Revista Brasileira de Medicina Veterinária, v.2, p.60, 1999.

PARDI, M.C; SANTOS, I.F.; SOUZA, E.R.; PARDI, H.S. Ciência, higiene e tecnologia da carne. 2.ed. Goiânia: Editora UFG, 2001. v.1.

PEREIRA, A.S.C.; LOPES, M.R.F. Manejo pré-abate e qualidade da carne. 2006. 6f. [Artigo Técnico]. Disponível em: <http:/ / www.carneangus.org.br>. Acesso em: 10 abr. 2008.

ROÇA, R. de O. Abate humanitário de bovinos. Revista de Educação Continuada, v.4, n.2, p.73-85, 2001.

ROUQUAYROL, M.Z.; ALMEIDA FILHO, N. de. Epidemiologia e saúde. 6.ed. Rio de Janeiro: Medsi, 2003. $708 \mathrm{p}$.
SANTOS, A.G. dos; GOMES, K.G.; MENDES, C. de G.; SILVA, R.C. da R.; SILVA, J.B.A. da Avaliação das condições físicas e higiênico-sanitárias no abate industrial de bovinos no Município de Mossoró-RN. In: CONGRESSO NACIONAL DE SAÚDE PÚBLICA VETERINÁRIA, 2., 2007, Fortaleza. Anais. Fortaleza: 2007. p.299.

SAVAGE, S. A practical look at its effect on intestine emptying, contamination and yield. 1998. Disponível em: <http://www.gov.mb.ca/agriculture/livestock/ poultry/bba01s26.html>. Acesso em: 12 abr. 2008.

SCHETTINO, D.N.; CANÇADO, S.V.; BAIÃO, N.C.; LARA, L.J.C.; FIGUEIREDO, T.C.; SANTOS, W.L.M. Efeito do período de jejum pré-abate sobre o rendimento de carcaça de frango de corte. Arquivo Brasileiro de Medicina Veterinária e Zootecnia, v.58, n.5, p.918-924, 2006

SCHOENHALS, M. Avaliação da eficiência do processo de flotação aplicado ao tratamento primário de efluentes de abatedouro avícola Florianópolis - SC. 2006. 99f. Dissertação (Mestrado em Engenharia Química) - Universidade Federal de Santa Catarina, Florianópolis, 2006. Disponível em: <http://www2.enq.ufsc.br/teses/m152.pdf>. Acesso em: 10 abr. 2008.

SILVA, J.A. As novas perspectivas para o controle sanitário dos alimentos. Higiene Alimentar, v.13, n.65, p.19-25. 1999.

WALTZ, E.; CORTEZ, N.M.S.; CORTEZ, M.A.S. Importância do departamento de inspeção final na qualidade da carne. Higiene Alimentar, v.21, n.150, p.104-105, 2007.

Recebido em 16/5/08

Aceito em 14/5/09 